Human Ethology Bulletin 31 (2016)2: 17-29

Research Article

\title{
The Young Male SYNDROME REVISITED - HOMICIDE DATA FROM HUNGARIAN AND AUSTRALIAN Populations
}

\author{
Péter Farsang \& Ferenc Kocsor \\ Institute of Psychology, University of Pécs, Pécs, Hungary \\ kocsorferenc@gmail.com
}

\begin{abstract}
Conspecific aggression is the result of competition for scarce resources. This holds for humans as well: competitiveness, risk taking and violence are primarily the result of reproductive competition between men. The occurrence of these behaviors in the population most intensely straining after success is referred to as the Young Male Syndrome (YMS). The observation that in homicide almost identical victim and offender populations are involved, with unemployed, unmarried young men greatly overrepresented, led to the inference that many, perhaps most, homicides are status competitions typically evolving from a "trivial altercation". In this paper Hungarian and Australian homicide data are tested and discussed in the light of the YMS and former data. Both Hungarian and Australian data correspond only partially with former findings. As expected, males are overrepresented amongst both victim and offender population and offenders are young. However, male victims in both countries are significantly older than male offenders. Hungarian male victims are even older than the average male population in the country. Consequently, the universality of the correspondence between the age of victims and offenders of homicide has not been corroborated. This does not narrow the validity of the evolutionary explanations of risk taking behavior and aggressive acts in general. However, though evolved psychological mechanisms may influence the willingness to solve conflicts and proceed in the dominance hierarchy by means of antagonistic acts, and even murder, social factors are likely to contribute more to the cross-cultural differences in age distribution of homicide victims.
\end{abstract}

Key words: Aggression, risk taking, cultural differences. 


\section{INTRODUCTION}

\section{The relationship between age and aggression}

According to Hirschi and Gottfredson (1983, p. 550), "one of the few facts agreed on in criminology is the age distribution of crime". Irrespective of sex, race, social groups or historical times, the relationship between age and frequency of crime shows a similar picture. The tendency to commit crimes grows fast in the teenage years, peaks at late adolescence or young adulthood, shows a steep decline and then levels off during middle age (Kanazawa \& Still, 2000). This relationship between age and aggressive crime can be well explained from an evolutionary perspective. Women prefer those men who are able to provide resources (Buss, 2014), but to reach high status one often needs to take a risk. Furthermore, risk taking behavior in itself is often found to be attractive to women (Farthing, 2005; Jones et al., 2007; Kelly \& Dunbar, 2001). Aggressive crimes naturally fall into the category of risky acts and, correspondingly, these might offer a way for men to highlight their manly qualities. In several societies accepting challenges to fight is rewarded by increased status, while avoiding a fight might cause irreparable damage to a man's reputation (Buss \& Shackelford, 1997). The payoff of competitive, risky behaviors would be the highest if they peak at the age when reproductive competition is the fiercest (Bereczkei, 2003; Wilson \& Daly, 1985), which explains the age-crime relationship in evolutionary terms.

\section{Homicide and the Young Male Syndrome}

Wilson and Daly (1985), analyzing the homicide data of Detroit and other US cities, came to the conclusion that many, perhaps most homicides concern status competition. As shown in a classic study, $37 \%$ of homicides in Philadelphia were categorized as "altercation of relatively trivial origin; insult, curse, jostling, etc." (Wolfgang, 1958, cited in Wilson \& Daly, 1985). The authors of an authoritative staff report on criminal homicide in 17 American cities concluded that "altercations appeared to be the primary motivating forces both here and in previous studies... many homicides are spontaneous acts of passion, not products of a single determination to kill" (Mulvihill, Tumin, \& Curtis 1969, cited in Wilson and Daly, 1985, p. 59). Wilson and Daly (1985) found that in the city of Detroit in 1972 the participants in homicidal conflicts tended to be similar: unemployed, single, young men. Dominance status and the "presentation of self" (Goffman, 1959) are behind these fights. Such findings led Wilson and Daly to introduce the concept of the Young Male Syndrome

arguing that if variations in the intensity of sexual selection have been relevant to the evolution of competitive inclinations and dangerous risk taking, young males would have been the most prone to this strategy.

Evidence for the disproportionate distribution of murders in the two sexes comes from many sources. In the world, with the single exception of Syria, men commit far more violent crimes than women (Kanazawa \& Still, 2000). Sixty-five percent of all homicides are due to male-male conflicts, $22 \%$ are committed by men against women, $10 \%$ by women against 
men and only $3 \%$ are the result of female-female conflicts (Duntley \& Buss, 2011). As far as age is concerned, various researchers investigated different countries and historical ages and received very similar age-crime curves. For example, data were reported on criminal offenders in England and Wales in 1842-44 (Neison, 1857, cited in Hirschi \& Gottfredson, 1983), conviction rate in England in 1908 (Goring, 1913, cited in Hirschi \& Gottfredson, 1983), age distribution of delinquency in Argentina in the 1960s (DeFleur, 1970, cited in Hirschi \& Gottfredson, 1983), arrest rate for all offences in the United States in 1977 (Hirschi \& Gottfredson, 1983), homicide rates in Canada between 1974 and 1992, and in Chicago between 1965 and 1989 (Daly \& Wilson, 2001). To our knowledge, and as far as homicide is concerned, the similarity between the age distribution of male offenders and that of male victims is convincingly supported only by US data (Wilson \& Daly, 1985). The similarity of socioeconomic profile and marital status of male offenders and male victims is also demonstrated by US and partly Canadian data (Daly \& Wilson, 2001; Wilson \& Daly, 1985).

In general, men are more willing to take risk and engage in violent acts all over the world. This universality stems directly and perhaps inevitably from the evolutionary constraints posed to men by intrasexual competition. Nevertheless, it could be problematic to define the range of phenomena for which evolutionary theory is a valid explanation. As detailed above, there are some studies which showed that males', especially young males' risky strategies extend to the domain of homicide. Moreover, the data suggest that they constitute not only the major proportion of offenders, but they are more likely to end up as victims, too. However, as these latter results are not backed up convincingly with cross-cultural data, the applicability of evolutionary theory as an explanatory framework for offender-victim age similarity needs caution: a focus on demographic and social processes at a particular place and historical period might be warranted as well.

\section{Objectives}

To our best knowledge, since the YMS was first published, no attempts were made to confirm some of the original observations on a larger sample. Most importantly, whether the similarity of the age of victims and offenders is a universal pattern, or the result of a couple of somewhat arbitrary processes in the society which are detached from evolutionary constraints, is not clear.

The current paper aims at comparing actual homicide data from Hungary and Australia with the demographic constitution of victims and offenders found in the study of Daly and Wilson (1985). Our analysis seeks answers to the following questions:

(1) Is the sex distribution of offenders in line with that of the population?

(2) Is the sex distribution of victims in line with that of the population?

(3) Is the age distribution of male offenders in line with that of the population?

(4) Is the age distribution of male victims in line with that of the population?

(5) Is the age distribution of male offenders in line with that of male victims? 
If the demographic properties of the populations in focus are similar to what was found earlier, answers to questions (1) to (4) should be "no", whereas to question (5) should be "yes", or at least the two samples should be fairly similar. In other words, we expect to find more males and young people ( $<35$ years) amongst both the offender and the victim groups. This would support the idea that a significant proportion of homicide cases result indeed from escalating conflicts between young men striving for status and resources. Hence, the pattern observed in US cities in the 70's, and other instances of the YMS reflecting young male's higher exposure to violence, is universal, therefore a promising subject to evolutionary explanations. Deviations from the predicted distribution, on the other hand, would necessitate the involvement of other factors into the analysis.

\section{METHOD}

\section{Data collection}

To collect Hungarian data, we analyzed the known victims and registered offenders of homicide cases by sex and age group, between January 2011 and December 2013. The Hungarian data were provided by the Department of Coordination and Statistics, Ministry of Domestic Affairs, Hungary. Out of the various homicide categories we used the "complete" and "on purpose" categories, unless otherwise stated. For data on the Hungarian population we referred to the Hungarian Statistical Yearbook 2012 (Hungarian Central Statistical Office, 2012).

To collect Australian data, we analyzed the known victims and registered offenders of homicide cases by sex and age group, between July 2008 and June 2010. The source of the Australian homicide data is the report entitled Homicide in Australia: 2008-09 to 2009-10 National Homicide Monitoring Program annual report, published by the Australian Institute of Criminology (Chan \& Payne, 2013). Homicide refers to a person killed (unlawfully) and is defined by the criminal law of each Australian state and territory and thus, various definitions exist in terms of its degree, culpability and intent. The data presented below reflects the operational definition used by the Australian police. There is one notable difference compared to the Hungarian data: the presented Australian data does include manslaughter. Manslaughter in Australia amounted to $12 \%$ of all homicides in the examined period (Chan \& Payne, 2013). For data on the Australian population we referred to the Australian Demographic Statistics, December 2010, (Australian Bureau of Statistics, n.d.).

\section{Statistical analysis}

All comparisons were made with SPSS 21, using one-sample and Pearson's chi-square tests. We tested frequency data (i.e., the number of people in each age group) of the subpopulations (e.g., Hungarian male victims) against the expected frequencies in the age groups of the respective population (e.g., Hungarian male population). We categorized people below 35 years as young. In other words, we tested whether the pattern of the age distribution of victims and offenders differs from that of the total population. Deviation 
from this pattern would suggest an effect of age. Differences in the sex ratios were calculated similarly. As the age of young people is considered in some studies below 34, while in others between 18 and 34, we used both methods to maintain comparability. The percentage figures in the results section refer to the former method, nevertheless the results coincide for both analyses except one single case (see Table 5).

\section{RESULTS}

\section{Hungarian data}

There were 389 homicide cases registered in Hungary for the years 2011 through 2013, of which the victim is known in 377 cases. That makes a total number of 460 offenders (Table 1). The numbers of offenders and victims do not necessarily match as one victim - several offenders cases as well as several victims - one offender cases are both possible. The statistical analysis shows that males are highly and significantly overrepresented among the offenders $(83 \%)$, as compared to the whole population. Sixty percent of victims are males which is also different from the pattern of the population. Age breakdown of male offenders (Tab. 2) differs from that of the male population: with other words, young males are heavily overrepresented amongst offenders. However, in contrast with the result of the first YMSstudy (Wilson \& Daly, 1985), the age breakdown of male offenders and that of male victims differ significantly (Fig 1). Three-quarters of male victims but only $45 \%$ of male offenders are above 35 years (see Tab. 1). Hungarian male victims, however, are not only old in comparison to male offenders. They are also older than the average male population. See Table 5 for more details on the statistical analysis.

Table 1: Known victims and registered offenders in Hungarian homicide cases (2011-2013)

\begin{tabular}{ccccccc}
\hline & \multicolumn{3}{c}{ HUN victims (2011-13) } & \multicolumn{2}{c}{ HUN offenders (2011-13) } \\
\cline { 2 - 7 } Age group & Men & Women & Total & Men & Women & Total \\
\hline $0-13$ & 11 & 9 & $\mathbf{2 0}$ & 0 & 0 & $\mathbf{0}$ \\
$14-17$ & 5 & 4 & $\mathbf{9}$ & 22 & 3 & $\mathbf{2 5}$ \\
$18-24$ & 8 & 9 & $\mathbf{1 7}$ & 86 & 11 & $\mathbf{9 7}$ \\
$25-34$ & 30 & 17 & $\mathbf{4 7}$ & 102 & 17 & $\mathbf{1 1 9}$ \\
$35-59$ & 111 & 64 & $\mathbf{1 7 5}$ & 147 & 47 & $\mathbf{1 9 4}$ \\
$60+$ & 62 & 47 & $\mathbf{1 0 9}$ & 23 & 2 & $\mathbf{2 5}$ \\
\hline Total & $\mathbf{2 2 7}$ & $\mathbf{1 5 0}$ & $\mathbf{3 7 7}$ & $\mathbf{3 8 0}$ & $\mathbf{8 0}$ & $\mathbf{4 6 0}$ \\
\hline share of 0-34 & $24 \%$ & $26 \%$ & $25 \%$ & $55 \%$ & $39 \%$ & $52 \%$ \\
share of 35+ & $76 \%$ & $74 \%$ & $75 \%$ & $45 \%$ & $61 \%$ & $48 \%$ \\
\hline Source: Hongayyyyyy
\end{tabular}

Source: Hungarian Central Statistical Office 
Table 2: Age breakdown of male victims, male offenders of Hungarian homicide cases (2011-2013) and of Hungarian male population (average of 2011 and 2013). Number of victims and offenders per 100.000 per annum.

\begin{tabular}{cccccc}
\hline $\begin{array}{c}\text { Age } \\
\text { group }\end{array}$ & $\begin{array}{c}\text { Male } \\
\text { offenders }\end{array}$ & $\begin{array}{c}\text { Male } \\
\text { victims }\end{array}$ & $\begin{array}{c}\text { HUN Male } \\
\text { population }\end{array}$ & $\begin{array}{c}\text { Male offender rate } \\
\text { (per 100,000 per } \\
\text { annum) }\end{array}$ & $\begin{array}{c}\text { Male victim rate } \\
\text { (per 100,000 per } \\
\text { annum) }\end{array}$ \\
\hline $0-13$ & 0 & 11 & 689308 & 0,0 & 0,5 \\
$14-17$ & 22 & 5 & 223010 & 3,3 & 0,7 \\
$18-24$ & 86 & 8 & 450908 & 6,4 & 0,6 \\
$25-34$ & 102 & 30 & 721878 & 4,7 & 1,4 \\
$35-59$ & 147 & 111 & 1737980 & 2,8 & 2,1 \\
$60+$ & 23 & 62 & 906844 & 0,8 & 2,3 \\
\hline Total & $\mathbf{3 8 0}$ & $\mathbf{2 2 7}$ & $\mathbf{4 7 2 9 9 2 7}$ & $\mathbf{2 , 7}$ & $\mathbf{1 , 6}$ \\
\hline
\end{tabular}

Source: Hungarian Central Statistical Office

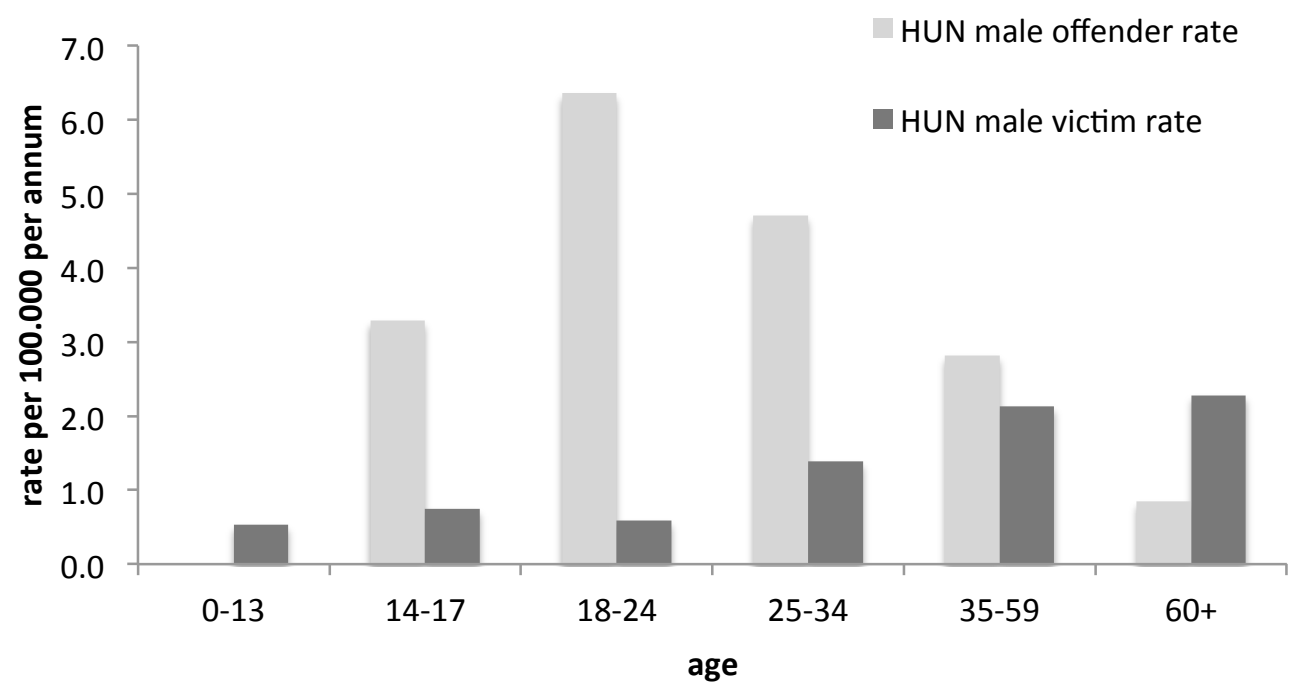

Figure 1: Hungarian male offenders vs. Hungarian male victims, by age groups, as per 100.000 persons within the same age group. 
The offender rate reflects the well-known crime-age curve, peaking at 18-24, then dropping steeply thereafter. However, male victim rate shows a totally different pattern. At 18-24 the victim rate is less than half of that of age group 25-34. The victim rate increases by a further $50 \%$ from $25-34$ to $35-59$ and there is a slight increase even from $60+$.

\section{Australian data}

There were 510 homicide cases in Australia registered for the period between July 1, 2008 and June 30,2010. The total number of offenders was 609, while the total number of victims was 541 (Tab. 3). Males accounted for $88 \%$ of offenders and $68 \%$ of victims (Tab. 4 ). Both numbers are significantly different from the sex ratio of the Australian population. The age breakdown of male offenders differs from that of the male population which shows that the share of young male offenders is disproportionately high (Fig 2). But in contrast what one would expect based on Wilson and Daly's (1985) data, the age split of male offenders and that of male victims are different. Sixty percent of male offenders, but only $45 \%$ of male victims are younger than 35 (see Tab. 3). See Table 5 for more details on the statistical analysis.

Table 3. Known victims and registered offenders in Australian homicide cases (July 2008 through June 2010)

\begin{tabular}{ccccccc}
\hline & \multicolumn{2}{c}{ AUS victims (07.2008-06.2010) } & \multicolumn{2}{c}{ AUS offenders (07.2008-06.2010) } \\
\cline { 2 - 7 } Age group & Men & Women & Total & Men & Women & Total \\
\hline$<1$ & 7 & 5 & $\mathbf{1 2}$ & 0 & 0 & $\mathbf{0}$ \\
$1-14$ & 16 & 11 & $\mathbf{2 7}$ & 6 & 0 & $\mathbf{6}$ \\
$15-17$ & 7 & 3 & $\mathbf{1 0}$ & 31 & 1 & $\mathbf{3 2}$ \\
$18-24$ & 53 & 16 & $\mathbf{6 9}$ & 136 & 6 & $\mathbf{1 4 2}$ \\
$25-34$ & 81 & 38 & $\mathbf{1 1 9}$ & 135 & 22 & $\mathbf{1 5 7}$ \\
$35-49$ & 111 & 55 & $\mathbf{1 6 6}$ & 149 & 29 & $\mathbf{1 7 8}$ \\
$50-64$ & 58 & 16 & $\mathbf{7 4}$ & 47 & 7 & $\mathbf{5 4}$ \\
$65+$ & 31 & 26 & $\mathbf{5 7}$ & 12 & 3 & $\mathbf{1 5}$ \\
\hline Total & $\mathbf{3 6 4}$ & $\mathbf{1 7 0}$ & $\mathbf{5 3 4}$ & $\mathbf{5 1 6}$ & $\mathbf{6 8}$ & $\mathbf{5 8 4}$ \\
\hline share of 0-34 & $45 \%$ & $43 \%$ & $44 \%$ & $60 \%$ & $43 \%$ & $58 \%$ \\
share of $35+$ & $55 \%$ & $57 \%$ & $56 \%$ & $40 \%$ & $57 \%$ & $42 \%$ \\
\hline
\end{tabular}

* Excluding 7 victims ( 2 men, 5 women) and 25 offenders ( 22 men, 3 women) with no age reported. Source: Australian Demographic Statistics 
Table 4. Age breakdown of male victims, male offenders of Australian homicide cases (2011-2013) and of Australian resident male population (at June 30,2010). Number of victims and offenders per 100.000 per annum.

\begin{tabular}{cccccc}
\hline Age group & Male offenders & $\begin{array}{c}\text { Male } \\
\text { victims }\end{array}$ & $\begin{array}{c}\text { AUS male } \\
\text { population }\end{array}$ & $\begin{array}{c}\text { Male } \\
\text { offender rate } \\
\text { (per 100,000 } \\
\text { per annum) }\end{array}$ & $\begin{array}{c}\text { Male } \\
\text { victim rate } \\
\text { (per 100,000 } \\
\text { per annum) }\end{array}$ \\
\hline$<1$ & 0 & 7 & 154426 & 0,0 & 2,3 \\
$1-14$ & 6 & 16 & 2015847 & 0,1 & 0,4 \\
$15-17$ & 31 & 7 & 452591 & 3,4 & 0,8 \\
$18-24$ & 136 & 53 & 1168140 & 5,8 & 2,3 \\
$25-34$ & 135 & 81 & 1610752 & 4,2 & 2,5 \\
$35-49$ & 149 & 111 & 2353390 & 3,2 & 2,4 \\
$50-64$ & 47 & 58 & 1985325 & 1,2 & 1,5 \\
$65+$ & 12 & 31 & 1376633 & 0,4 & 1,1 \\
\hline Total $^{*}$ & $\mathbf{5 1 6}$ & $\mathbf{3 6 4}$ & $\mathbf{1 1 1 1 7 1 0 4}$ & $\mathbf{2 , 3}$ & $\mathbf{1 , 6}$ \\
\hline
\end{tabular}

* Excluding 2 male victims (0.5\%) and 2 male offenders (4.1\%) with no age reported.

Source: Australian Demographic Statistics

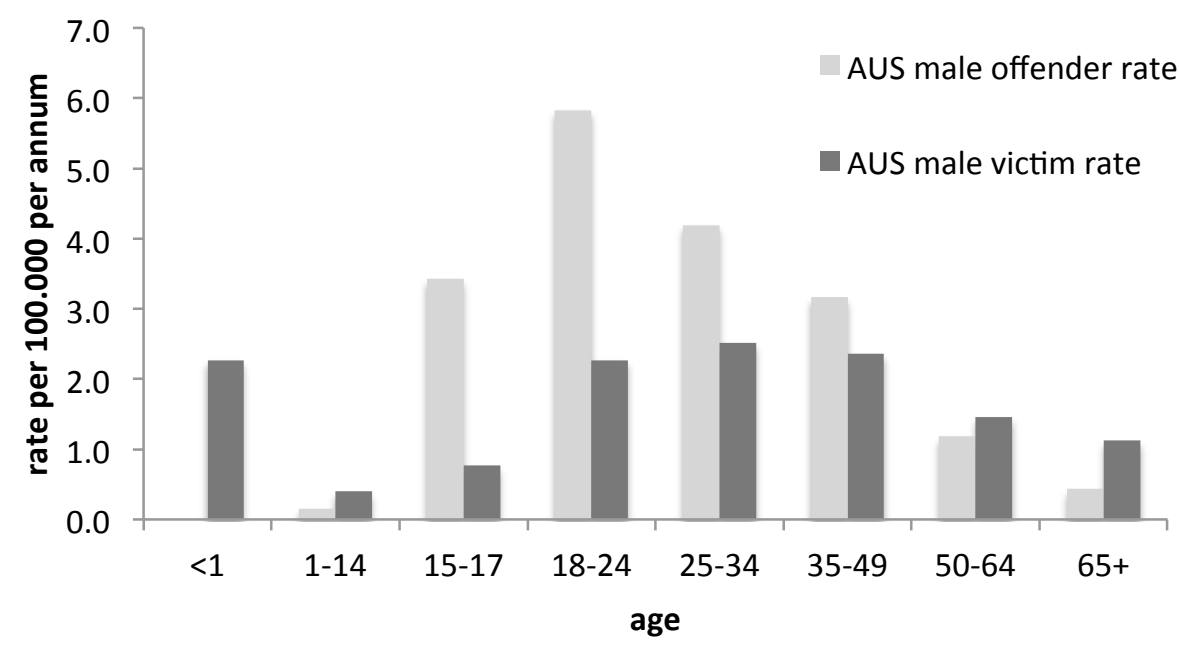

Figure 2. Australian male offenders vs. Australian male victims, by age group, as per 100.000 persons within the same age group. 
Table 5. Summary of the chi-square tests. ${ }^{*}$ Results are significant $(P<0.05)$.

\begin{tabular}{|c|c|c|c|c|c|c|}
\hline $\begin{array}{c}\text { Statistical } \\
\text { comparison }\end{array}$ & $\begin{array}{l}\text { Age interval of } \\
\text { young people (0- } \\
34 \text { or 18-34) }\end{array}$ & $\begin{array}{c}\text { Sample } \\
\text { (country) }\end{array}$ & Grouping & $x^{2}$ & $\begin{array}{c}P, \text { Risk } \\
\text { Ratio/Odds } \\
\text { Ratio }^{a}\end{array}$ & \\
\hline \multirow{4}{*}{$\begin{array}{l}\text { sex ratio of } \\
\text { offenders vs. sex } \\
\text { ratio of } \\
\text { population }\end{array}$} & $0+$ & \multirow{2}{*}{ AUS } & \multirow{4}{*}{$\begin{array}{l}\text { male, } \\
\text { female }\end{array}$} & 362.12 & $<0.001^{*}$ & 7.6 \\
\hline & $18+$ & & & 323.15 & $<0.001^{*}$ & 7.3 \\
\hline & $0+$ & \multirow{2}{*}{ HUN } & & 226.7 & $<0.001^{*}$ & 5.2 \\
\hline & $18+$ & & & 221.91 & $<0.001^{*}$ & 5.3 \\
\hline \multirow{4}{*}{$\begin{array}{l}\text { sex ratio of } \\
\text { victims vs. sex } \\
\text { ratio of } \\
\text { population }\end{array}$} & $0+$ & \multirow{2}{*}{ AUS } & \multirow{4}{*}{$\begin{array}{l}\text { male, } \\
\text { female }\end{array}$} & 68.99 & $<0.001^{*}$ & 2.1 \\
\hline & $18+$ & & & 74.45 & $<0.001^{*}$ & 2.3 \\
\hline & $0+$ & \multirow{2}{*}{ HUN } & & 24.24 & $<0.001^{*}$ & 1.7 \\
\hline & $18+$ & & & 26.59 & $<0.001^{*}$ & 1. \\
\hline \multirow{4}{*}{$\begin{array}{l}\text { age split of male } \\
\text { offenders vs. age } \\
\text { split of male } \\
\text { population }\end{array}$} & $0+$ & \multirow{2}{*}{ AUS } & $0-34,35+$ & 25.47 & $<0.001^{*}$ & 1.6 \\
\hline & $18+$ & & $18-34,35+$ & 123.14 & $<0.001^{*}$ & 2.7 \\
\hline & $0+$ & \multirow{2}{*}{ HUN } & $0-34,35+$ & 19.27 & $<0.001^{*}$ & 1.6 \\
\hline & $18+$ & & $18-34,35+$ & 79.84 & $<0.001^{*}$ & 2.5 \\
\hline \multirow{4}{*}{$\begin{array}{l}\text { age split of male } \\
\text { victims vs. age } \\
\text { split of male } \\
\text { population }\end{array}$} & $0+$ & \multirow{2}{*}{ AUS } & $0-34,35+$ & 1.83 & 0.176 & 0.9 \\
\hline & $18+$ & & $18-34,35+$ & 8.51 & $<0.004^{*}$ & 1.4 \\
\hline & $0+$ & 5 & $0-34,35+$ & 37.93 & $<0.001^{*}$ & 0.4 \\
\hline & $18+$ & & $18-34,35+$ & 16.21 & $<0.001^{*}$ & 0.5 \\
\hline \multirow{4}{*}{$\begin{array}{l}\text { age split of male } \\
\text { victims vs. age } \\
\text { split of male } \\
\text { offenders }\end{array}$} & $0+$ & \multirow{2}{*}{ AUS } & $0-34,35+$ & 18.38 & $<0.001^{*}$ & 0.6 \\
\hline & $18+$ & & $18-34,35+$ & 21.32 & $<0.001^{*}$ & 0.5 \\
\hline & $0+$ & \multirow{2}{*}{ HUN } & $0-34,35+$ & 57.28 & $<0.001^{*}$ & 0.3 \\
\hline & $18+$ & & $18-34,35+$ & 66.01 & $<0.001^{*}$ & 0.2 \\
\hline
\end{tabular}

${ }^{a}$ Risk ratios were calculated for the comparisons between a subgroup and the whole population (e.g., sex ratio of offenders vs. sex ratio of population), whereas odds ratio was calculated for the comparison of two subgroups (age split of male victims vs. age split of male offenders). 


\section{DISCUSSION}

We found significantly more males than females amongst the offenders of registered homicide cases in both countries. This is no surprise and is rather similar to the data previously reported by others (see Duntley \& Buss, 2011; Wilson \& Daly, 1985). The age breakdown of offenders is also in line with what the perspective of evolutionary theory in general, or the Young Male Syndrome in particular, would suggest. The same point can be made about the sex ratio of the victims: significantly more of them were males. However, the age breakdown of male victims in both countries differs from the data of Wilson and Daly (1985). In fact, in Hungary it shows the opposite picture: older males have higher chances of becoming victims than younger ones. Their deaths cannot be explained by the fight between young men who are in the age classes "that have experienced the most intense reproductive competition (fitness variance) during the species' evolutionary history", as was originally proposed by Wilson and Daly (1985, p. 59).

Why do the Australian and Hungarian homicide data fail to confirm our expectations implied by existing data when it comes to the age split of male victims? One may argue that some of these homicide cases must have been incidental to the commission of another crime, like robbery or similar. But in the case of Australia, the data clearly show that only a small portion of the crime could fall into this category. As with the annual report of the National Homicide Monitoring Program only 6\% of the homicide incidents were labeled as money being the apparent motive (Chan \& Payne, 2013). In the case of Hungary it is unclear what percentage of the homicide was incidental to the commission of another crime like robbery.

While the distorting effects of crimes like robberies probably do not explain the different age distribution, it is possible to search for alternative explanations. Note that most of the empirical data supporting the notion that a high percentage of homicides originate from a "trivial altercation" of young men, in fact, comes from the United States (Daly \& Wilson, 1990; Kanazawa \& Still, 2000; Mulvihill et. al. 1969, cited in Wilson \& Daly, 1985; Wolfgang 1958, cited in Wilson \& Daly, 1985). Homicide data from Canada for the period 1974 to 1983 was also presented from the same point of view, but those data are at best equivocal as the risk of being killed even increased after age 34, and started to drop more only from age group 45-49 (Daly \& Wilson, 1988).

The US differs from Hungary and Australia concerning the culture associated with, and the availability of, firearms to private individuals. In Hungary the regulations for the carriage and usage of firearms by private individuals are amongst the most restrictive ones in Europe (Horváth, 2009). As for Australia, the country's states and territories, provoked into action by 35 deaths in a single shooting spree, in the late 1990s agreed to new uniform legislation, the primary declared purpose of which was to reduce the risk of mass shootings. The country also launched a firearms buyback program and bought back and destroyed at least 600,000 guns (Alpers, 2013). As a general comment we would like to note here that, 
assuming a well-functioning central government, a very liberal firearms legislation in itself is probably a necessary but hardly sufficient prerequisite of widespread gun usage.

We have no reason to doubt that "trivial altercations" between young men in Australia or Hungary are just as tense as amongst their counterparts in the US. But the difference is that the former one, even in a desperate state of mind, are not in the position to put an end to the quarrel just by pressing the trigger of a gun. It is safe to assume that the lack of firearms significantly reduces the number of lethal injuries that the participants of such fights may suffer. The usage of alternative means (say, a pocket knife) of immediate retaliation in a hand-to-hand combat involve a far greater risk on behalf of the attacker, especially when the physical fitness of the parties is comparable. The situation may be different if there is 1020-year age gap between those involved. In such case the chances of the two parties are often not equal, and, thus, the younger party may find hand-to-hand combat an acceptable solution. The importance of the non-availability of firearms is supported by the Australian data. In the examined years only $13 \%$ of the victims met their fate from firearms (Chan \& Payne, 2013). This compares to the FBI's data showing that in the US between 2007 and $201167 \%$ of murder victims died from firearm violence in general, and $48 \%$ from handgun violence (FBI, 2011). The respective Hungarian data are not available. Thus, we suggest that possibly the main cause of the difference between the age split of male victims in Hungary and Australia vs. the US is that in the former countries a much higher percentage of the status fights between young men end deathlessly due to differences in the society (like non-availability of firearms and different culture of gun usage).

\section{CONCLUSIONS}

A cogent contribution to the account of why aggression and risk taking are particularly prevalent in young males, the so called Young Male Syndrome, is offered by evolutionary theory. Such behavior, it is suggested, is primarily the result of reproductive competition in those age-sex classes where the reproductive competition was the most intense during evolutionary history. Homicide is seen as an extreme outcome of competitiveness, therefore, we could expect that the same populations are involved as in less violent forms of competition. In the current study the major features of the Young Male Syndrome have been replicated, with homicidal offending being more prevalent in young males and this is consistent with other available data on the demographic pattern observed for risky behavior generally. The Hungarian and Australian data presented here do not support the universality of almost identical victim and offender populations that was found in previous studies. However this does not weaken the central evolutionary argument that the pervasiveness of aggression and other risk taking in young males, was selected for during male-male competition for resources, especially mates. In modern times, this evolved mechanism drives homicidal aggression in young males, but it could be directed at victims of any age, as the current data found. 
To account for why the profile of victims might differ between samples in different cultures, we identified one of many possible factors, namely the availability of firearms, which might crucially influence whether antagonistic acts become homicidal, but more detailed analysis in further studies might reveal other factors.

\section{ACKNOWLEDGEMENT}

The authors are grateful to the Department of Coordination and Statistics, Ministry of Domestic Affairs, Hungary, for providing the respective Hungarian data.

\section{REFERENCES}

Alpers, P. (2013). The Big Melt. How One Democracy Changed after Scrapping a Third of Its Firearms. In D. W. Webster \& J. S. Vernick (Eds.), Reducing Gun Violence in America: Informing Policy with Evidence and Analysis. Baltimore: Johns Hopkins University Press.

Australian Bureau of Statistics. (n.d.). Australian Demographic Statistics, Dec 2010. Retrieved from http://www.abs.gov.au/AUSSTATS/abs@.nsf/DetailsPage/3101.0Dec\%202010?OpenDoc ument

Bereczkei, T. (2003). Evolúciós pszichológia. Budapest: Osiris Kiadó Kft. Retrieved from http://www.libri.hu/konyv/bereczkei_tamas.evolucios-pszichologia.html

Buss, D. (2005). The handbook of evolutionary psychology. John Wiley \& Sons. Retrieved from https://www.google.com/books?hl=hu\&lr=\&id=esDW3xTKoLIC\&oi=fnd\&pg=PR7\&ots= N6Mp1tnmqO\&sig=Rfk6DiXbHzvgoo9Sed9lbXPdQ 8. DOI

Buss, D. (2014). Evolutionary Psychology: The New Science of the Mind: Pearson New International Edition. Pearson Education Limited.

Buss, D., \& Shackelford, T. K. (1997). Human aggression in evolutionary psychological perspective. Clinical Psychology Review, 17(6), 605-619. DOI

Campbell, A. (1999). Staying alive: Evolution, culture, and women's intrasexual aggression. Behavioral and Brain Sciences, 22(02), 203-214. DOI

Chan, A., \& Payne, J. (2013). Homicide in Australia: 2008-09 to 2009-10 National Homicide Monitoring Program annual report. Australian Institute of Criminology. Retrieved from http://www.ssaa.org.au/research/2013/2013-02-20_homicide-in-australia-2008-to2009-10national-monitoring-program.pdf

Daly, M., \& Wilson, M. (1988). Homicide. Transaction Publishers. Retrieved from https://www.google.com/books?hl=hu\&lr=\&id=3p4br9FRAUgC\&oi=fnd\&pg=PR9\&dq= Daly,+M.,+and+Wilson, + M.+(1988).+Homicide\&ots=kvjuQwJ_bL\&sig=_1t4T4btr9kI91o i_scVmSRra-U

Daly, M., \& Wilson, M. (1990). Killing the competition. Human Nature, 1(1), 81-107. DOI 
Daly, M., \& Wilson, M. (2001). Risk-taking, intrasexual competition, and homicide. In Symposium on motivation (Vol. 47, pp. 1-36). Retrieved from http://psycserv.mcmaster.ca/bennett/psy720/readings/m2/dalyWilson2001.pdf

Duntley, J. D., \& Buss, D. M. (2011). Homicide adaptations. Aggression and Violent Behavior, 16(5), 399-410. DOI

Farthing, G. W. (2005). Attitudes toward heroic and nonheroic physical risk takers as mates and as friends. Evolution and Human Behavior, 26(2), 171-185. DOI

FBI. (2011). Crime in the United States 2011. Murder Victims by Weapon 2007-2011. Retrieved from https://www.fbi.gov/about-us/cjis/ucr/crime-in-the-u.s/2011/crime-in-the-u.s.2011/tables/expanded-homicide-data-table-8

Goffman, E. (1959). The presentation of self in everyday life. Garden City, NY: Doubleday Anchor Books.

Hirschi, T., \& Gottfredson, M. (1983). Age and the explanation of crime. American Journal of Sociology, 552-584. DOI

Horváth, E. (2009). Fegyvertartás itthon és Európában - A fegyverviselés szabályairól. Retrieved from http://www.jogiforum.hu/hirek/22259

Hungarian Central Statistical Office. (2012). Magyar Statisztikai Évkönyv, 2012.

Jones, B. C., DeBruine, L. M., Little, A. C., Conway, C. A., Welling, L. L., \& Smith, F. (2007). Sensation seeking and men's face preferences. Evolution and Human Behavior, 28(6), 439446. DOI

Kanazawa, S., \& Still, M. C. (2000). Why men commit crimes (and why they desist). Sociological Theory, 18(3), 434-447. http://doi.org/doi: 10.1111/0735-2751.00110

Kelly, S., \& Dunbar, R. I. (2001). Who dares, wins. Human Nature, 12(2), 89-105. DOI

Wilson, M., \& Daly, M. (1985). Competitiveness, risk taking, and violence: The young male syndrome. Ethology and Sociobiology, 6(1), 59-73. DOI 